\section{Bright spots physical activity investments that work: Youth-Physical Activity Towards Health (Y-PATH)}

\author{
Sarahjane Belton, ${ }^{1}$ Wesley O'Brien, ${ }^{2}$ Jamie McGann, ${ }^{1}$ Johann Issartel ${ }^{1}$
}

\section{BACKGROUND TO THE PROGRAMME}

The problem of low levels of youth physical activity (PA) participation in Ireland and internationally is clear and irrefutable. ${ }^{12}$ The Youth-Physical Activity Towards Health (Y-PATH) programme commenced in 2010, with cross-sectional research exploring predisposing and reinforcing factors influencing low levels of Irish youth PA participation (including fundamental movement skill (FMS) proficiency, and attitudes, motivation and knowledge towards PA). ${ }^{3}$ In consultation with key stakeholders a targeted 'wholeschool' intervention programme was developed on the basis of this research. ${ }^{3}$

\section{KEY PROGRAMME FEATURES}

Y-PATH is a multicomponent schoolbased programme, based on a combination of self-determination theory, ${ }^{4}$ and the socioecological model..$^{5}$ The 'active ingredients' shown in figure 1 can be broken down into three categories (1) Physical education (PE) component, 'PE 4 ME', (2) Whole-school teacher component. (3) Parent/guardian component. ${ }^{3}$ The whole-school teacher component targets all teachers to act as change agents and supportive role models for PA promotion in the school environment. The parent/guardian component recognises the crucial role which parents play in supporting, and actively role modelling positive PA

The most critical of the Y-PATH components is the PE element 'PE 4 $\mathrm{ME}$ '. As part of this central domain, PE teachers receive a continuing professional development (CPD) module on the effective delivery of the Y-PATH programme. Students are exposed over a 3-year 'Junior Cycle' period (age 12-15 years, approximately) to Y-PATH 'PE 4 ME' which maps onto

\footnotetext{
School of Health and Human Performance, Dublin City University, Dublin, Ireland

${ }^{2}$ School of Education, University College Cork, Cork, Ireland
}

Correspondence to Dr Sarahjane Belton, School of Health and Human Performance, Dublin City University, Dublin 9, Ireland; sarahjane.belton@dcu.ie behaviour. and supports fully the state PE curriculum. Y-PATH 'PE 4 ME' advocates that the fundamental purpose of PE is to 'enable every child to lead a sustained physically active life', and all PE curricular content is therefore taught through this lens. To achieve this purpose, the programme emphasises the integration of both health-related activity and FMS learning through all other PE content. Teachers learn to foster and deliver PE through a motivational climate, with a focus on self-efficacy and student motivation.

\section{BREADTH AND REACH}

To date, 46 specialist PE teachers in the Ireland have received $\mathrm{CPD}$, and are currently delivering the Y-PATH programme in their respective education practices. These teachers teach a minimum of four Junior Cycle class groups per year, with an average of 25 students per class group. Teachers have been delivering Y-PATH in their schools for between 2 years and 5 years depending on year trained. Conservative estimations from these figures suggest that well over 10000 youth have received the Y-PATH programme in the schools trained to date. Over 1500 young people have been involved directly in the Y-PATH research.

In 2018, a partnership was forged between Dublin City University and key national agencies including the Irish Heart Foundation, University College Cork, Sport Ireland and the Professional Development

\section{Programme card}

\section{Country/locality/coverage}

- Republic of Ireland, national coverage

Target population

- Children aged 12-15years; first year to third year postprimary school youth

What modes/types/domains of physical activity does the programme promote?

- Total physical activity, moderate to vigorous physical activity and reducing sedentary behaviour

Which of the seven best investments does the programme address?

- The programme addresses two of the seven investments; Health Education and Education

What sectors does it involve?

- Health Education and Education

\section{Estimated programme reach}

- With a current average of 62000 students in each of the 3 years at Junior Cycle, this gives an estimated reach of 186000 children over this initial 3-year period, and a further estimated 62000 children (annual first year intake nationally) for each year of commitment after that

\section{What is special about this programme?}

- Youth-Physical Activity Towards Health (Y-PATH) is a whole school programme, reaching out to physical education (PE) class, all teachers and parents. Crucially, Y-PATH fully supports delivery of the existing national PE curriculum in schools so does not create additional workload for PE teachers, and has the support of key national agencies for PE teacher education, postprimary education, sports and health

Key contact

- Dr Sarahjane Belton (sarahjane.belton@dcu.ie)

Programme website

- https://www.irishheart.ie/courses/y-path 


\section{Active Ingredients of the Y-PATH Programme}

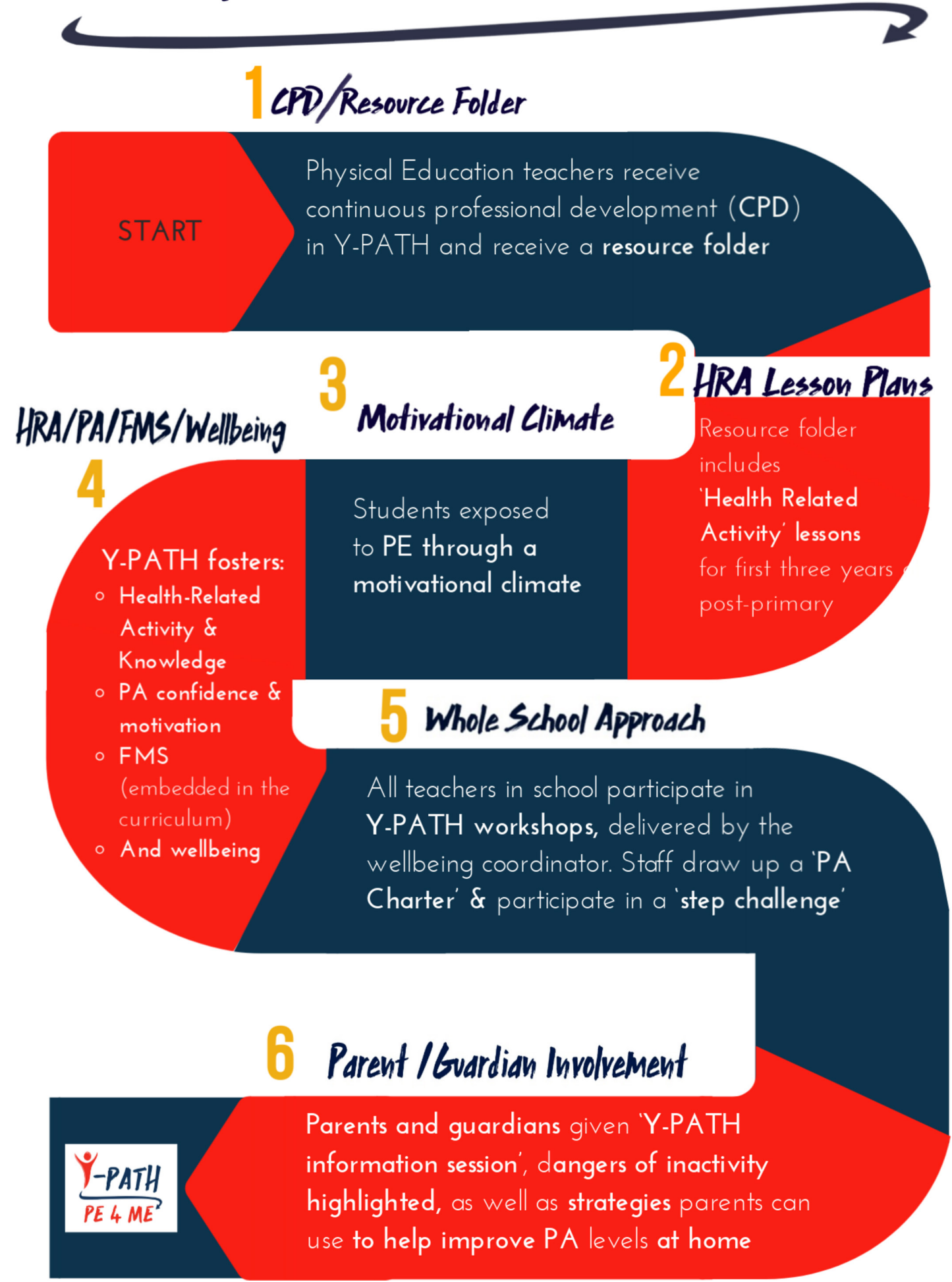

Figure 1 Active ingredients of the Youth-Physical Activity Towards Health (Y-PATH) programme. FMS, fundamental movement skill; PA, physical activity; PE, physical education.

Service for Teachers. Under this partnership the Irish Heart Foundation has made an indefinite commitment for national roll-out of the Y-PATH programme. This engagement means that two PE teachers in every postprimary school in Ireland $(n=714)$ will be offered CPD in the Y-PATH programme between 2018 and 2021. With a current average of 62000 students in each of the 3 years at Junior Cycle this gives a projected reach of 186000 young people over this initial 3-year period, and a further estimated 62000 (annual first year intake nationally) for each year of commitment after that as shown in figure 2. 

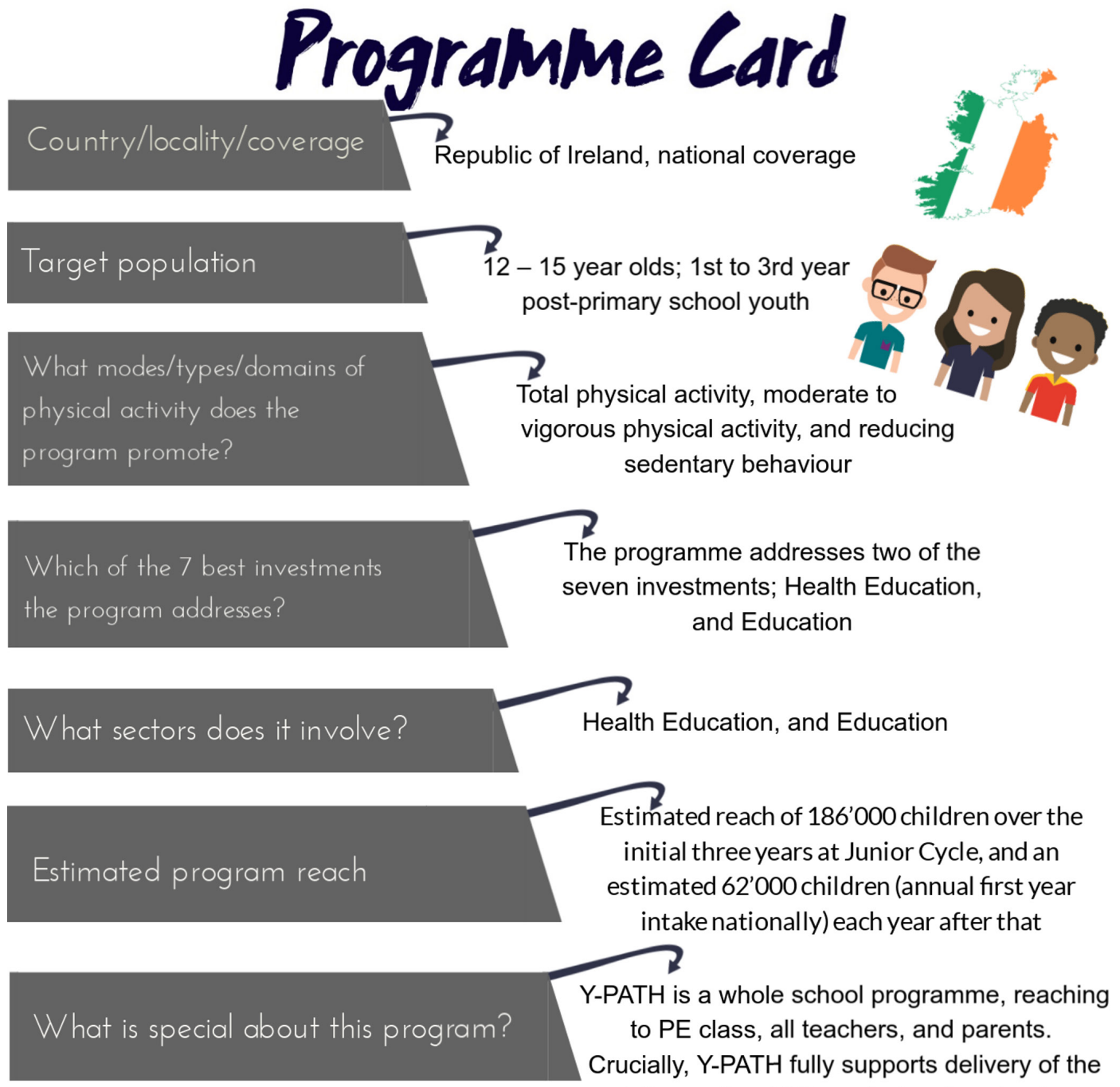

Y-PATH is a whole school programme, reaching to PE class, all teachers, and parents. Crucially, Y-PATH fully supports delivery of the existing national PE curriculum in schools so

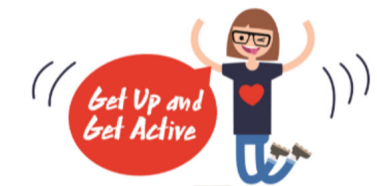
does not create additional workload for PE teachers, and has the support of key national agencies for $\mathrm{PE}$ teacher education, post primary education, sport and health

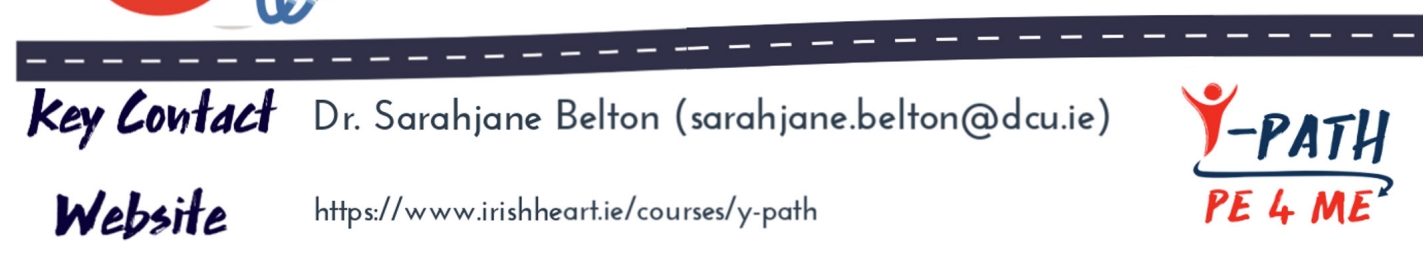

Figure 2 Y-PATH programme card. PE, physical education; Y-PATH, Youth-Physical Activity Towards Health.

\section{WHY IT WORKS?}

Y-PATH started as a small, focused study, but crucially with a target on national impact from inception. The key stakeholders of students and teachers were involved in the programme development and refinement throughout. This ensured that Y-PATH would work in practice, as well as being based on robust theory and research findings. Other national stakeholders (eg, the Irish Heart Foundation) were invited to contribute to programme development from its inception, anticipating the crucial role they would play at the dissemination phase.

As shown in figure 3, the Y-PATH intervention was evaluated initially in a two-school exploratory controlled trial in 2012, with findings showing the programme to be effective in increasing moderate-to-vigorous physical activity (MVPA) levels, and overall FMS proficiency in youth. ${ }^{6}$ The Y-PATH programme was subsequently refined based on this exploratory work, ${ }^{6}$ and evaluated in a formal 2-year cluster randomised-controlled trial (RCT), involving 20 Irish postprimary schools (2014-2016). ${ }^{7}$ Results from this RCT confirmed the programme was effective in improving youth FMS proficiency. ${ }^{7}$ In addition, youth in the Y-PATH intervention group maintained minutes of MVPA over time, while youth in the control condition declined by an average of $6 \mathrm{~min}^{8}$ 
- PAT4 Youth-Physical Activity Towards Health PE $4 M E$

A targeted whole school intervention programme to address low levels of PA in Irish post-primary youth
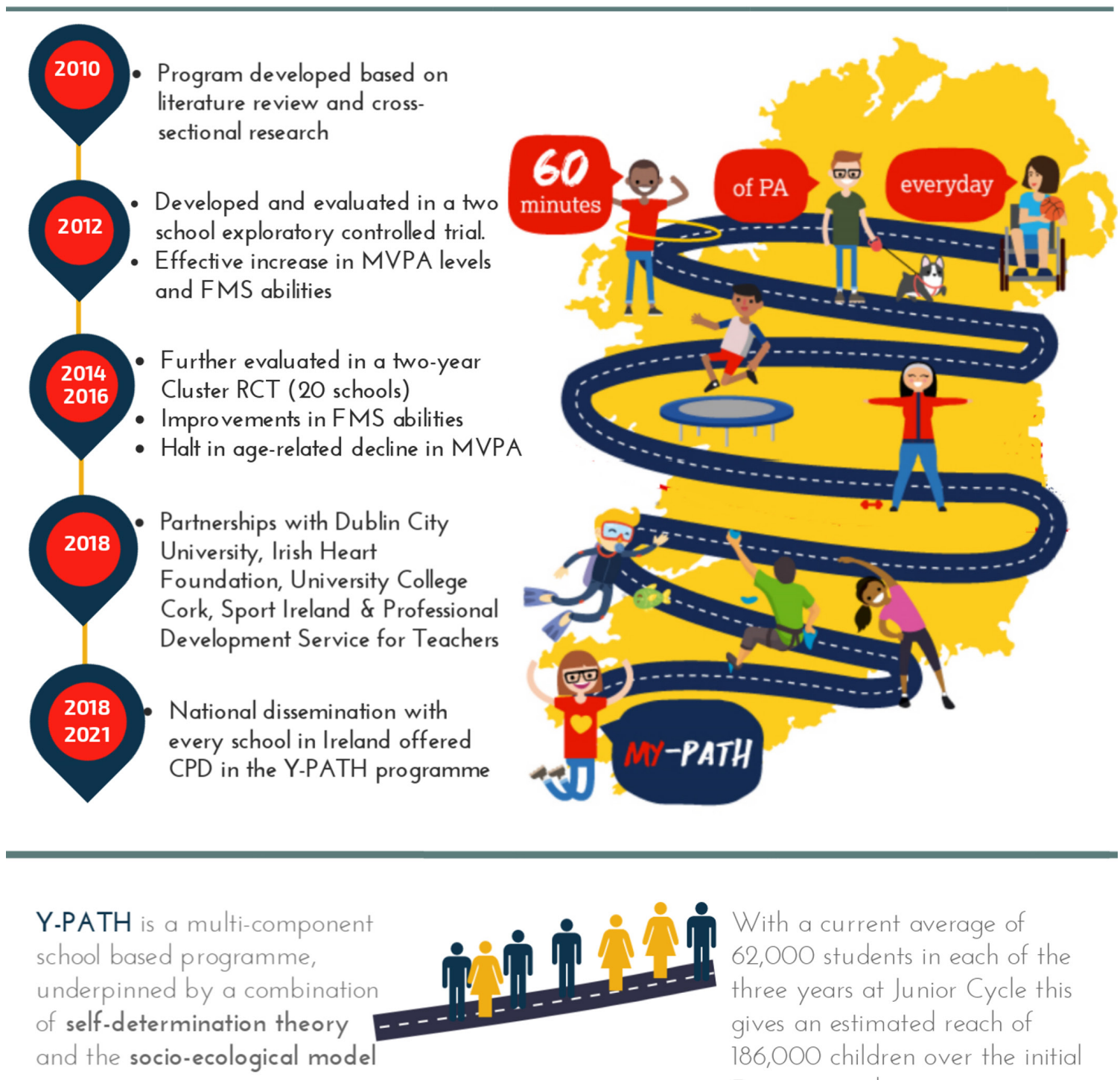

With a current average of 62,000 students in each of the three years at Junior Cycle this gives an estimated reach of 186,000 children over the initial 3-year period
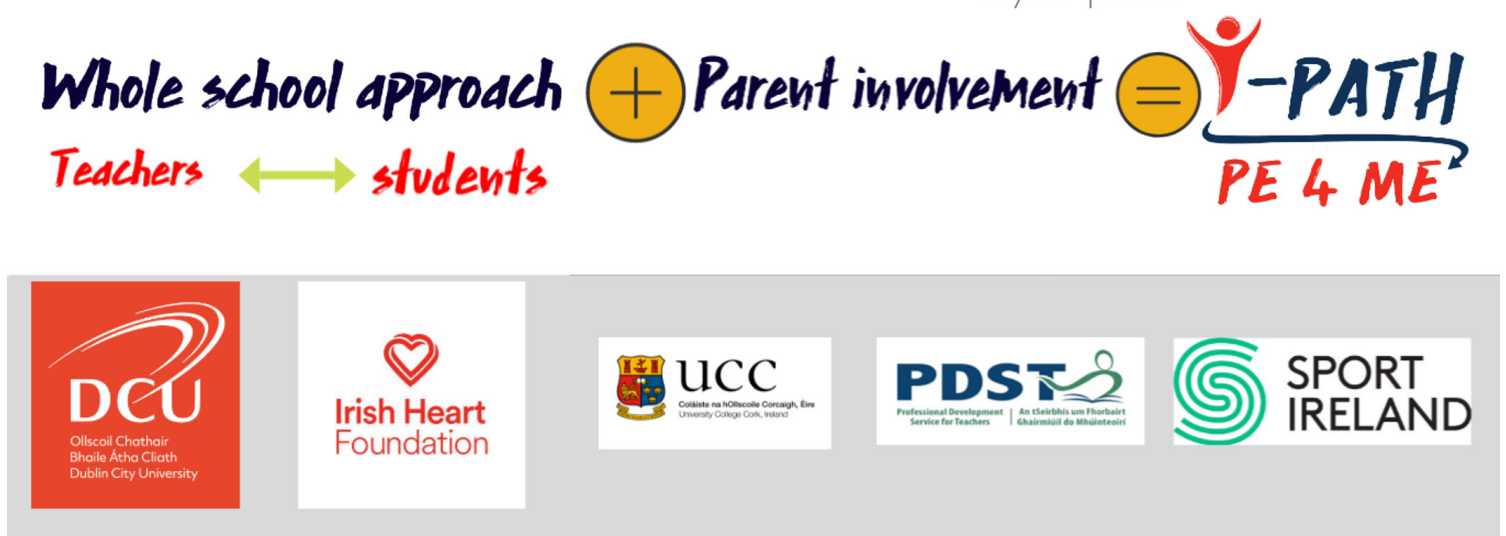

Figure 3 Y-PATH programme infographic. CPD, continuing professional development; FMS, fundamental movement skill; MVPA, moderate-tovigorous physical activity; PA, physical activity; PE, physical education; RCT, randomised-controlled trial. 


\section{LESSONS LEARNT FOR FUTURE PA PROGRAMMES}

The success of Y-PATH rests on the iterative and collaborative nature of its development. Y-PATH was designed for, through, and with students and teachers in schools, as a direct response to their needs. Expanding the Y-PATH programme to an older cohort of adolescents and younger adults seems important to consider.

Acknowledgements The authors thank all the teachers and students from the schools involved in the project for their support.

Contributors SB led the article and developed the first draft. JI and WO'B revised the article and provided subsequent drafts. JM developed the graphics, which were reviewed by the remaining authors. All authors have been heavily involved in the study design, data collection and dissemination of the Y-PATH intervention to date.

Funding This study was funded by Dublin City University and Dublin Local Sports Partnerships.

Competing interests None declared.

Patient consent Not required.

Ethics approval Dublin City University Research Ethics Committee.

Provenance and peer review Not commissioned; internally peer reviewed.
(6)

\section{OPEN ACCESS}

Open access This is an open access article distributed in accordance with the Creative Commons Attribution Non Commercial (CC BY-NC 4.0) license, which permits others to distribute, remix, adapt, build upon this work non-commercially, and license their derivative works on different terms, provided the original work is properly cited, appropriate credit is given, any changes made indicated, and the use is non-commercial. See: http:// creativecommons.org/licenses/by-nc/4.0/.

(C) Author(s) (or their employer(s)) 2019. Re-use permitted under CC BY-NC. No commercial re-use. See rights and permissions. Published by BMJ.

\section{Check for updates}

To cite Belton S, O'Brien W, McGann J, et al. Br J Sports Med 2019;53:208-212.

Accepted 16 September 2018 Published Online First 12 October 2018

Br J Sports Med 2019;53:208-212.

doi:10.1136/bjsports-2018-099745

\section{REFERENCES}

1 Woods C, Moyna N, Quinlan A, et al, 2010. The Children's Sport Participation and Physical
Activity Study (CSPPA Study). Report 1. https:// www.sportireland.ie/Research/Childrens_Sports Participation_and_Physical_Activity_Study/CSPPA_ Study_Report_2010_/

2 Hallal PC, Bauman AE, Heath GW, Bo Andersen L, Bull F, et al. Physical activity: more of the same is not enough. Lancet 2012;380:190-1.

3 Belton S, O' Brien W, Meegan S, et al. Youth-Physical Activity Towards Health: evidence and background to the development of the Y-PATH physical activity intervention for adolescents. BMC Public Health 2014;14:122.

4 Ryan RM, Patrick H, Deci EL, et al. Facilitating health behaviour change and its maintenance : Interventions based on self-determination theory. Eur Heal Psychol 2008;10:2-5.

5 McLeroy KR, Bibeau D, Steckler A, et al. An ecological perspective on health promotion programs. Health Educ Q 1988;15:351-77.

6 O’ Brien W, Issartel J, Belton S. Evidence for the efficacy of the Youth-Physical Activity towards Health (Y-PATH) Intervention. Advances in Physical Education 2013;03:145-53.

7 McGrane B, Belton S, Fairclough SJ, et al. Outcomes of the Y-PATH Randomized controlled trial: can a schoolbased intervention improve fundamental movement skill proficiency in adolescent youth? I Phys Act Health 2018;15:89-98.

8 Belton S, Issartel J, McGrane B, et al; Y-PATH (YouthPhysical Activity Towards Health): a school based intervention for promoting physical activity in youth, 2015. HEPA Europe Annual Conference. 